\title{
Formulation and Evaluation of Floating Oral In Situ Gelling System of Amoxicillin
}

\author{
Dasharath M. Patel, Divyesh K. Patel, and Chhagan N. Patel \\ Department of Pharmaceutics, Shri Sarvajanik Pharmacy College, Near Arvind Baug, Mehsana, Gujarat 384 001, India \\ Correspondence should be addressed to Dasharath M. Patel, justdmpatel@rediffmail.com
}

Received 31 March 2011; Accepted 8 May 2011

Academic Editors: F. Fernández and G. Ragno

Copyright (๑) 2011 Dasharath M. Patel et al. This is an open access article distributed under the Creative Commons Attribution License, which permits unrestricted use, distribution, and reproduction in any medium, provided the original work is properly cited.

Purpose. Effective Helicobacter pylori eradication requires delivery of the antibiotic locally in the stomach. High dose of amoxicillin ( 750 to $1000 \mathrm{mg}$ ) is difficult to incorporate in floating tablets but can easily be given in liquid dosage form. Keeping the above facts in mind, we made an attempt to develop a new floating in situ gelling system of amoxicillin with increased residence time using sodium alginate as gelling polymer to eradicate $H$. pylori. Methods. Floating in situ gelling formulations were prepared using sodium alginate, calcium chloride, sodium citrate, hydroxypropyl methyl cellulose K100, and sodium bicarbonate. The prepared formulations were evaluated for solution viscosity, floating lag time, total floating time, and in vitro drug release. The formulation was optimized using a $3^{2}$ full factorial design. Dissolution data were fitted to various models to ascertain kinetic of drug release. Regression analysis and analysis of variance were performed for dependent variables. Results. All formulations $\left(F_{1}-F_{9}\right)$ showed floating within $30 \mathrm{~s}$ and had total floating time of more than $24 \mathrm{~h}$. All the formulations showed good pourability. It was observed that concentration of sodium alginate and HPMC K100 had significant influence on floating lag time, cumulative percentage drug release in $6 \mathrm{~h}$ and $10 \mathrm{~h}$. The batch $F_{8}$ was considered optimum since it showed more similarity in drug release $\left(f_{2}=74.38\right)$ to the theoretical release profile. Conclusion. Floating in situ gelling system of amoxicillin can be formulated using sodium alginate as a gelling polymer to sustain the drug release for 10 to $12 \mathrm{~h}$ with zero-order release kinetics.

\section{Introduction}

Helicobacter pylori (H. pylori) is one of the most common pathogenic bacterial infections. It is associated with the development of serious gastroduodenal disease, including peptic ulcers, gastric lymphoma, and acute chronic gastritis. $H$. pylori resides mainly in the gastric mucosa or at the interface between the mucous layer and the epithelial cells of the antral region of the stomach. Antibiotics required for eradication of $H$. pylori are high in dose and in more frequencies [1]. This is because of the low concentration of the antibiotic reaching the bacteria under the mucosa, instability of the drug in the low $\mathrm{pH}$ of gastric fluid, and short residence time of the antibiotic in the stomach, leading to incomplete eradication of $H$. pylori.

Amoxicillin is a semisynthetic, orally absorbed, broadspectrum antibiotic. It is widely used in a standard eradication treatment of gastric $H$. pylori infection combined with a second antibiotic and an acid-suppressing agent [2]. As conventional drug delivery systems do not remain in the stomach for prolonged periods, they are unable to deliver the amoxicillin to the site of infection in effective concentrations. Therefore, it is necessary to design drug delivery systems that not only alleviate the shortcomings of conventional delivery vehicles but also deliver amoxicillin to the infected cell lines. Some researchers had prepared and reported new amoxicillin formulations, such as floating tablets $[3,4]$, mucoadhesive tablets [5], and mucoadhesive microspheres [6], which were able to reside in stomach for an extended period for more effective $H$. pylori eradication. Amongst the described formulations, the floating tablet is preferred for better and less variable gastric retention, but it has a limitation of incorporation of high dose of the drug. The drug with high dose like amoxicillin can be easily incorporated in liquid in situ gelling formulation that upon oral administration can float for a prolonged period of time in the stomach. 
TABLE 1: Formulation of amoxicillin in situ gel using different concentrations of calcium chloride and sodium citrate.

\begin{tabular}{|c|c|c|c|}
\hline \multirow{2}{*}{$\begin{array}{l}\text { Name of } \\
\text { ingredient }\end{array}$} & \multicolumn{3}{|c|}{ Quantity in $100 \mathrm{~mL}(\% \mathrm{w} / \mathrm{v})$} \\
\hline & $I-1$ & $I-2$ & $I-3$ \\
\hline Amoxicillin & 7.5 & 7.5 & 7.5 \\
\hline $\begin{array}{l}\text { Calcium } \\
\text { chloride }\end{array}$ & 0.075 & 0.10 & 0.15 \\
\hline Sodium citrate & 0.25 & 0.33 & 0.5 \\
\hline Sodium alginate & 2.5 & 2.5 & 2.5 \\
\hline HPMC K100 & 0.8 & 0.8 & 0.8 \\
\hline $\begin{array}{l}\text { Sodium } \\
\text { bicarbonate }\end{array}$ & 1.5 & 1.5 & 1.5 \\
\hline Deionised water & Q.S & Q.S & Q.S \\
\hline Gelling strength & $\begin{array}{c}\text { Open } \\
\text { network gel }\end{array}$ & $\begin{array}{c}\text { Open } \\
\text { network gel }\end{array}$ & $\begin{array}{c}\text { Close network } \\
\text { Stiff gel }\end{array}$ \\
\hline $\mathrm{CPR}$ & $100($ in $3 \mathrm{~h})$ & $100($ in $5 \mathrm{~h})$ & 70.14 (in $6 \mathrm{~h})$ \\
\hline
\end{tabular}

CPR indicates cumulative percentage release; HPMC K100 indicates hydroxypropyl methyl cellulose K100; Q.S indicates quantity sufficient.

Keeping the above facts in mind, we made an attempt to develop a new floating in situ gelling system of amoxicillin with increased residence time using sodium alginate as gelling polymer [7] and hydroxypropyl methyl cellulose K100 (HPMC K100) as thickening agent [8] with a potential of H. Pylori eradication. The proposed new sodium alginatebased amoxicillin floating in situ gelling systems would have the advantage of ease of administration, as being a liquid, and also be more patient compliant.

\section{Materials and Methods}

2.1. Materials. Amoxicillin and hydroxypropyl methylcellulose K100 (HPMC K100) were purchased from Yarrow Chem. Products, Mumbai, India. Sodium alginate was obtained from Finar Chemicals Pvt. Ltd, Ahmedabad, India. Sodium bicarbonate was obtained from Shakti Chemicals, Mehsana, India. Calcium chloride and sodium alginate were obtained from Chemdyes Corporation, Ahmedabad, India. All other materials and chemicals used were of either pharmaceutical or analytical grade.

\subsection{Methods}

2.2.1. Preparation of In Situ Gelling Solution. Sodium alginate, at different concentrations $(2 \% \mathrm{w} / \mathrm{v}, 2.5 \% \mathrm{w} / \mathrm{v}$, and $3 \% \mathrm{w} / \mathrm{v}$ ), was prepared in deionised water containing calcium chloride $(0.15 \% \mathrm{w} / \mathrm{v})$ and sodium citrate $(0.5 \% \mathrm{w} / \mathrm{v})$. HPMC $\mathrm{K} 100(0.3 \% \mathrm{w} / \mathrm{v}, 0.6 \% \mathrm{w} / \mathrm{v}$, and $0.9 \% \mathrm{w} / \mathrm{v})$ was added to it. The sodium alginate solution was heated to $50^{\circ} \mathrm{C}$ with stirring. After cooling below $40^{\circ} \mathrm{C}, 1.5 \% \mathrm{w} / \mathrm{v}$ of calcium carbonate and drug were added and dispersed well with continuous stirring. The resulting sodium alginate in situ gel solution containing amoxicillin was finally stored in amber colour narrow mouth bottles until further use.

2.2.2. Measurement of Viscosity of In Situ Gelling Solution. The viscosities of the prepared solutions were determined
TABle 2: Formulation of amoxicillin in situ gel using different concentrations of sodium bicarbonate.

\begin{tabular}{lccc}
\hline $\begin{array}{l}\text { Name of } \\
\text { ingredient }\end{array}$ & \multicolumn{3}{c}{ Quantity in $100 \mathrm{~mL}(\% \mathrm{w} / \mathrm{v})$} \\
\hline $\begin{array}{l}\text { Amoxicillin } \\
\text { Calcium }\end{array}$ & 7.5 & 7.5 & $\mathrm{C}-3$ \\
$\begin{array}{l}\text { chloride } \\
\text { Sodium citrate }\end{array}$ & 0.15 & 0.15 & 0.15 \\
Sodium alginate & 2.5 & 0.5 & 0.5 \\
$\begin{array}{l}\text { HPMC K100 } \\
\text { Sodium }\end{array}$ & 0.8 & 2.5 & 2.5 \\
bicarbonate & 1 & 0.8 & 0.8 \\
$\begin{array}{l}\text { Deionised water } \\
\text { Floating lag }\end{array}$ & Q.S & 1.5 & 2 \\
time (s) & 55 & Q.S & Q.S \\
CPR at 6h (\%) & 67.50 & 48 & 30 \\
\hline
\end{tabular}

CPR indicates cumulative percentage release; HPMC K100 indicates hydroxypropyl methyl cellulose K100; Q.S indicates quantity sufficient.

by brook field viscometer (Brookfield viscometer, modelLVDV-II pro, USA). The samples $(100 \mathrm{~mL})$ were sheared at a rate of $100 \mathrm{r} / \mathrm{min}$ using suitable spindle at room temperature. Viscosity measurement for each sample was done in triplicate, with each measurement taking approximately $30 \mathrm{~s}$.

2.2.3. In Vitro Gelation Study. Gelation of in situ gelling solution was carried out by taking $500 \mathrm{~mL}$ of $0.1 \mathrm{~N}$ hydrochloric acid $(\mathrm{HCl}, \mathrm{pH} 1.2)$ in a beaker. Accurately measured $10 \mathrm{~mL}$ of solution was added to $\mathrm{HCl}$ with mild agitation that avoids breaking of formed gel. Gelling was observed visually by qualitative measurement.

2.2.4. In Vitro Floating Study. Floating study of in situ gelling solution was carried out in $500 \mathrm{~mL}$ of $0.1 \mathrm{~N} \mathrm{HCl}(\mathrm{pH} 1.2)$ in a beaker. Accurately measured $10 \mathrm{~mL}$ of solution was added to $\mathrm{HCl}$ with mild agitation. Time required for floating on surface after adding solution (floating lag time) and total floating time were measured $[9,10]$.

2.2.5. In Vitro Drug Release Study. The in vitro release rate of amoxicillin from sustained release in situ gel was performed using USP apparatus [11] (model TDT-08T, Electrolab, Mumbai, India) fitted with paddle $(50 \mathrm{r} / \mathrm{min})$ at $37 \pm 0.5^{\circ} \mathrm{C}$ using $500 \mathrm{~mL}$ of $0.1 \mathrm{~N} \mathrm{HCl}$ as a dissolution medium. This speed was slow enough to avoid the breaking of gelled formulation and was maintaining the mild agitation conditions believed to exist in vivo. At the predetermined time intervals, $10 \mathrm{~mL}$ samples were withdrawn, filtered through a $0.45 \mu \mathrm{m}$ membrane filter, diluted, and assayed at $272 \mathrm{~nm}$ using a Shimadzu UV 1800 double-beam spectrophotometer (Shimadzu, Kyoto, Japan). Cumulative percentage drug release (CPR) was calculated using an equation obtained from a calibration curve.

2.2.6. Preliminary Screening. The preliminary screening was performed to optimize amount of calcium chloride and sodium bicarbonate in the formulation. For optimization 
TABLE 3: Formulation and evaluation of batches in $3^{2}$ full factorial design.

\begin{tabular}{lcccccccc}
\hline Batch code & \multicolumn{2}{c}{ Variable levels in coded form } & FLT $(\mathrm{s})$ & $Q_{1}(\%)$ & $Q_{6}(\%)$ & $Q_{10}(\%)$ & $f_{2}$ & Viscosity (cps) \\
& $X_{1}$ & $X_{2}$ & & & & & & \\
\hline$F_{1}$ & -1 & -1 & 18 & 48.39 & 85.04 & 100.24 & 42.78 & 171.1 \\
$F_{2}$ & -1 & 0 & 15 & 47.41 & 82.82 & 100.37 & 45.51 & 186.3 \\
$F_{3}$ & -1 & 1 & 13 & 44.92 & 80.57 & 99.93 & 47.86 & 193.7 \\
$F_{4}$ & 0 & -1 & 21 & 44.92 & 80.57 & 99.93 & 48.01 & 211.3 \\
$F_{5}$ & 0 & 0 & 15 & 44.21 & 79.16 & 98.80 & 51.11 & 230.4 \\
$F_{6}$ & 0 & 1 & 10 & 41.99 & 77.55 & 98.61 & 54.48 & 356.7 \\
$F_{7}$ & 1 & 1 & 16 & 43.23 & 78.55 & 97.55 & 52.88 & 431.9 \\
$F_{8}$ & 1 & 0 & 12 & 42.88 & 67.03 & 85.02 & 74.38 & 542.1 \\
$F_{9}$ & 1 & 1 & 11 & 41.90 & 65.99 & 83.97 & 70.18 & 634.3 \\
\hline
\end{tabular}

Coded values Actual values

\begin{tabular}{lcc} 
& $X_{1}$ & $X_{2}$ \\
\hline-1 & $2 \%$ & $0.3 \%$ \\
0 & $2.5 \%$ & $0.6 \%$ \\
1 & $3 \%$ & $0.9 \%$
\end{tabular}

All batches contained $7.5 \%$ of amoxicillin, $1.5 \%$ of sodium bicarbonate, $0.15 \%$ of calcium chloride, and $0.5 \%$ of sodium citrate. $X_{1}$ indicates concentration of sodium alginate, $X_{2}$ concentration of HPMC K100. $Q_{1}, Q_{6}$, and $Q_{10}$ indicate percentage drug released after 1, 6, and $10 \mathrm{~h}$, respectively. FLT indicates floating lag time; $f_{2}$ indicates similarity factor.

of amount of calcium chloride, in situ gelling systems of amoxicillin were prepared using different concentration of calcium chloride and proportionally sodium citrate as shown in Table 1. Prepared in situ gelling systems were tested for gelling strength and CPR at $6 \mathrm{~h}$. For optimization of amount of sodium bicarbonate, in situ gelling systems of amoxicillin were prepared using different concentration of sodium bicarbonate as shown in Table 2. Prepared in situ gelling systems were tested for floating lag time (FLT) and $\mathrm{CPR}$ at $6 \mathrm{~h}$.

2.2.7. Optimization of Variables Using Full Factorial Design. A $3^{2}$ randomized full factorial design was used in the present study. In this design, 2 factors were evaluated, each at 3 levels, and experimental trials were performed for all 9 possible combinations [12]. The concentration of sodium alginate $\left(X_{1}\right)$ and concentration of HPMC K100 $\left(X_{2}\right)$ were chosen as independent variables in $3^{2}$ full factorial design, while FLT (floating lag time), $Q_{1}, Q_{6}$, and $Q_{10}$ (\% drug release after 1, 6, and 10 hours, resp.) were taken as dependent variables. The formulation layout for the factorial design batches $\left(F_{1}-F_{9}\right)$ is shown in Table 3.

2.2.8. Kinetic Modeling of Dissolution Data. The dissolution profile of all batches were fitted to various models such as zero order, first order, Higuchi [13], Hixon and Crowell [14], and Korsemeyer et al. [15], to ascertain the kinetic of drug release. The method described by Korsemeyer et al. was used to describe the mechanism of drug release.

2.2.9. Comparison of Release Profiles for Selection of Optimum Batch. The similarity factor $\left(f_{2}\right)$ given by SUPAC guidelines for a modified release dosage form was used as a basis to
TABLE 4: Summary of results of regression analysis.

\begin{tabular}{|c|c|c|c|c|c|c|}
\hline & $b_{0}$ & $b_{1}$ & $b_{2}$ & $b_{12}$ & $b_{11}$ & $b_{22}$ \\
\hline \multicolumn{7}{|c|}{ For FLT } \\
\hline \multicolumn{7}{|c|}{ Response (FLT) } \\
\hline FM & 14.77 & -1.16 & -3.5 & $-3.4 * 10^{-16}$ & -1.16 & 0.83 \\
\hline RM & 14.56 & - & -3.5 & - & - & - \\
\hline \multicolumn{7}{|c|}{ For $Q_{1}$} \\
\hline \multicolumn{7}{|c|}{ Response $\left(Q_{1}\right)$} \\
\hline FM & 44.11 & -2.12 & -1.29 & 0.53 & 1.09 & -0.69 \\
\hline $\mathrm{RM}$ & - & - & - & - & - & - \\
\hline \multicolumn{7}{|c|}{ For $Q_{6}$} \\
\hline \multicolumn{7}{|c|}{ Response $\left(Q_{6}\right)$} \\
\hline FM & 77.95 & -6.14 & -3.34 & -2.02 & -2.42 & 1.70 \\
\hline RM & 77.47 & -6.14 & - & - & - & - \\
\hline \multicolumn{7}{|c|}{ For $Q_{10}$} \\
\hline \multicolumn{7}{|c|}{ Response $\left(Q_{10}\right)$} \\
\hline FM & 97.79 & -5.66 & -2.53 & -3.31 & -4.6 & 1.97 \\
\hline RM & 96.04 & -5.66 & - & - & - & - \\
\hline
\end{tabular}

$\overline{F M}=$ Full model, $R M=$ Reduced model; $Q_{1}, Q_{6}$, and $Q_{10}$ indicate percentage of drug released after 1,6 , and $10 \mathrm{~h}$, respectively; FLT indicates floating lag time.

compare dissolution profiles. The dissolution profiles are considered to be similar when $f_{2}$ is between 50 and 100 . The dissolution profiles of products were compared using an $f_{2}$ which is calculated from the following formula:

$$
f_{2}=50 \times \log \left\{\left[1+\left(\frac{1}{n}\right) \sum_{t=1}^{n} w_{t}\left(R_{t}-T_{t}\right)\right]^{2} \times 100\right\},
$$


TABLE 5: Calculations for testing the model in portions.

\begin{tabular}{|c|c|c|c|c|c|c|}
\hline & $\mathrm{DF}$ & SS & MS & $F$ & $R^{2}$ & \\
\hline \multicolumn{7}{|c|}{ For floating lag time } \\
\hline \multicolumn{7}{|c|}{ Regression } \\
\hline FM & 5 & 85.77 & 17.15 & 4.13 & 0.87 & \multirow{5}{*}{$\begin{array}{l}F \text { calc. }=0.73 \\
F \text { table }=9.12 \\
D F=(4,3)\end{array}$} \\
\hline $\mathrm{RM}$ & 1 & 73.5 & 73.5 & 20.81 & 0.002 & \\
\hline Error & & & & & & \\
\hline FM & 3 & 12.44 & 4.15 & & & \\
\hline RM & 7 & 24.72 & 3.53 & & & \\
\hline \multicolumn{7}{|c|}{ For $Q_{6}$} \\
\hline \multicolumn{7}{|c|}{ Regression } \\
\hline FM & 5 & 327.42 & 65.48 & 8.71 & 0.935 & \multirow{5}{*}{$\begin{array}{l}F \text { calc. }=3.36 \\
F \text { table }=9.12 \\
D F=(4,3)\end{array}$} \\
\hline $\mathrm{RM}$ & 1 & 226.44 & 226.44 & 12.83 & 0.64 & \\
\hline Error & & & & & & \\
\hline FM & 3 & 22.54 & 7.51 & & & \\
\hline $\mathrm{RM}$ & 7 & 123.51 & 17.64 & & & \\
\hline \multicolumn{7}{|c|}{ For $Q_{10}$} \\
\hline \multicolumn{7}{|c|}{ Regression } \\
\hline FM & 5 & 325.37 & 65.07 & 7.83 & 0.92 & \multirow{5}{*}{$\begin{array}{l}F \text { calc. }=3.99 \\
F \text { table }=9.12 \\
\text { DF }=(4,3)\end{array}$} \\
\hline $\mathrm{RM}$ & 1 & 192.66 & 192.66 & - & 0.55 & \\
\hline Error & & & & & & \\
\hline $\mathrm{FM}$ & 3 & 12.44 & 4.15 & & & \\
\hline $\mathrm{RM}$ & 7 & 24.72 & 3.53 & & & \\
\hline
\end{tabular}

DF indicates the degree of freedom; SS: Sum of squares; MS: Mean of squares; $R^{2}$ : Regression coefficient; FM: Full model; RM, Reduced model. $Q_{6}$ and $Q_{10}$ indicate percentage of drug released after 6 and $10 \mathrm{~h}$, respectively.

where $n$ is the dissolution time, and $R_{t}$ and $T_{t}$ are the reference (here, this is the theoretical dissolution profile of amoxicillin) and test dissolution value at time $t$ [16].

2.2.10. Fourier Transform Infrared Spectroscopy. Fourier transform infrared (FTIR) spectra of amoxicillin, a physical mixture of amoxicillin-HPMC K100, and a physical mixture of amoxicillin-sodium alginate were recorded using $\mathrm{KBr}$ mixing method on FTIR instrument available at central instrument laboratory of the institute (FTIR-1700, Shimadzu, Kyoto, Japan).

\section{Results and Discussion}

3.1. Results of Preliminary Screening. Three batches (I-1, $I-2$, and $I-3$ ) were prepared to optimize amount of calcium chloride and proportionally sodium citrate. From the observation of gelling strength and CPR at $6 \mathrm{~h}$ of prepared batches as shown in Table 1, it was concluded that only batch $I-3$ (containing $0.15 \% \mathrm{w} / \mathrm{v}$ of calcium chloride) formed the closed network stiff gel and controlled the release of drug for more than $6 \mathrm{~h}$.

Three batches $(C-1, C-2$, and $C$-3) were prepared to optimize amount of sodium bicarbonate $\left(\mathrm{NaHCO}_{3}\right)$. From the observation of floating lag time and $\mathrm{CPR}$ at $6 \mathrm{~h}$ of prepared batches as shown in Table 2, it was concluded that batch $\mathrm{C}-2$ (containing $1.5 \% \mathrm{NaHCO}_{3}$ ) had optimum floating lag time (48 s) and CPR at $6 \mathrm{~h}(71.57)$.
3.2. Full Factorial Design. A statistical model incorporating interactive and polynominal terms was used to evaluate the responses

$$
Y=b_{0}+b_{1} X_{1}+b_{2} X_{2}+b_{12} X_{1} X_{2}+b_{11} X_{1} X_{1}+b_{22} X_{2} X_{2},
$$

where $Y$ is the dependent variable, $b_{0}$ is the arithmetic mean response of the 9 runs, and $b_{1}$ is the estimated coefficient for the factor $X_{i}$. The main effects $\left(X_{1}\right.$ and $X_{2}$ ) represent the average result of changing 1 factor at a time from its low to high values. The interaction terms $\left(X_{1} X_{2}\right)$ show how the response changes when two factors are simultaneously changed. The polynomial terms $\left(X_{1}^{2}\right.$ and $\left.X_{2}^{2}\right)$ are included to investigate nonlinearity. The release profile for 9 batches showed a variation (i.e., initial $1 \mathrm{hr}$ release ranging from $41.90 \%$ to $48.39 \%$ and drug released after $10 \mathrm{hr}$ ranging from $83.97 \%$ to $100.37 \%$ ). The data indicate that the release profile of the drug is strongly dependent on the selected independent variables. The fitted equations (full and reduced) relating the responses, FLT, $Q_{1}, Q_{6}$, and $Q_{10}$, to the transformed factor are shown in the Table 4 . The polynomial equations can be used to draw conclusions after considering the magnitude of coefficient and the mathematical sign it carries (i.e., negative or positive). Table 4 shows the results of analysis of variance (ANOVA), which was performed to identify insignificant factors. Data were analyzed using Microsoft Excel. 
TABLe 6: Kinetic treatment of dissolution data.

\begin{tabular}{|c|c|c|c|c|c|c|c|c|c|}
\hline & $F_{1}$ & $F_{2}$ & $F_{3}$ & $F_{4}$ & $F_{5}$ & $F_{6}$ & $F_{7}$ & $F_{8}$ & $F_{9}$ \\
\hline \multicolumn{10}{|c|}{ Zero order } \\
\hline$b$ & 5.17 & 5.27 & 5.42 & 5.45 & 5.44 & 5.89 & 5.78 & 4.59 & 4.42 \\
\hline$a$ & 47.48 & 45.72 & 43.66 & 43.52 & 42.24 & 37.46 & 38.33 & 40.13 & 40.10 \\
\hline$R^{2}$ & 0.9619 & 0.9713 & 0.9716 & 0.9692 & 0.9771 & 0.9844 & 0.9811 & 0.9969 & 0.9941 \\
\hline \multicolumn{10}{|c|}{ First order } \\
\hline$b$ & 0.030 & 0.031 & 0.033 & 0.033 & 0.033 & 0.036 & 0.035 & 0.029 & 0.029 \\
\hline$a$ & 1.699 & 1.686 & 1.668 & 1.667 & 1.657 & 1.619 & 1.626 & 1.637 & 1.634 \\
\hline$R^{2}$ & 0.9465 & 0.9554 & 0.9527 & 0.9496 & 0.9604 & 0.9702 & 0.9666 & 0.9874 & 0.9812 \\
\hline \multicolumn{10}{|c|}{ Higuchi } \\
\hline$b$ & 24.07 & 24.42 & 25.13 & 25.31 & 25.14 & 27.02 & 26.50 & 20.73 & 20.04 \\
\hline$a$ & 22.88 & 20.91 & 18.09 & 17.74 & 16.81 & 10.41 & 11.76 & 19.70 & 20.54 \\
\hline$R^{2}$ & 0.9832 & 0.9880 & 0.9892 & 0.9877 & 0.9905 & 0.9893 & 0.9873 & 0.9897 & 0.9901 \\
\hline \multicolumn{10}{|c|}{ Hixon Crowell } \\
\hline$b$ & -0.09 & -1.75 & -1.80 & -1.81 & -1.83 & -1.96 & -1.92 & -1.52 & -1.47 \\
\hline$a$ & 0.973 & 18.09 & 18.77 & 18.82 & 19.25 & 20.84 & 20.55 & 19.95 & 19.97 \\
\hline$R^{2}$ & -0.9525 & -0.9713 & -0.9715 & -0.9691 & -0.9775 & -0.9843 & -0.9810 & -0.9969 & -0.9940 \\
\hline \multicolumn{10}{|c|}{ Korsemeyer and Peppas } \\
\hline$n$ & 0.333 & 0.341 & 0.361 & 0.364 & 0.363 & 0.396 & 0.387 & 0.316 & 0.313 \\
\hline$a$ & -0.34 & -0.355 & -0.376 & -0.378 & -0.385 & -0.423 & -0.416 & -0.395 & -0.399 \\
\hline$R^{2}$ & 0.9845 & 0.9857 & 0.9885 & 0.9868 & 0.9877 & 0.9802 & 0.9756 & 0.9832 & 0.9859 \\
\hline
\end{tabular}

$b$ = slope, $a=$ intercept, $R^{2}=$ Square of correlation coefficient, and $n=$ diffusion exponent.

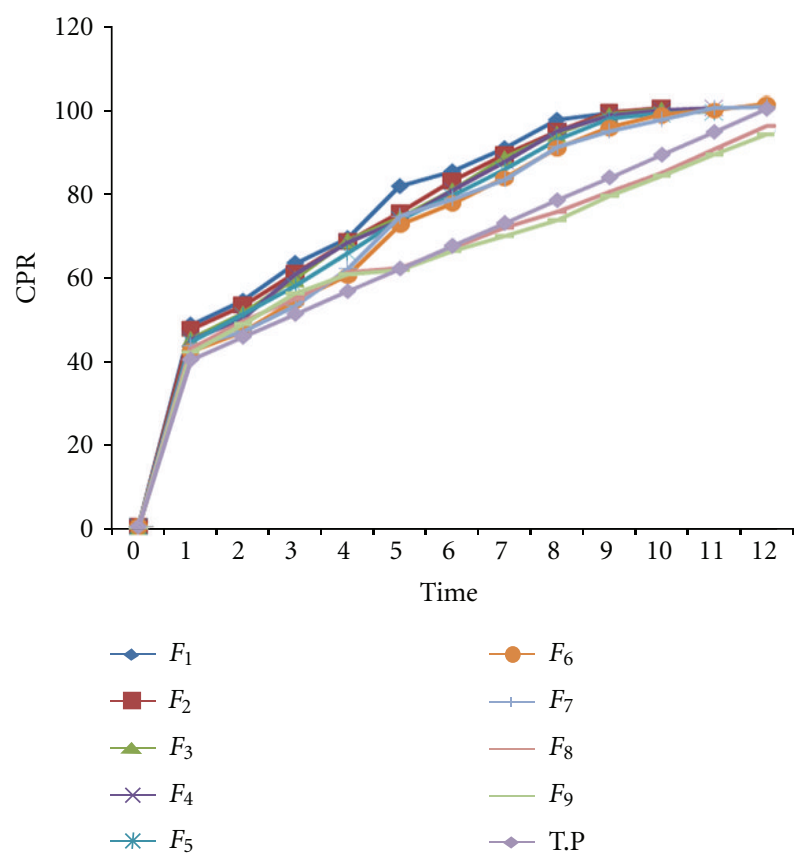

FIgURE 1: Comparison of dissolution profile.

$R^{2}$ value for FLT, $Q_{1}, Q_{6}$, and $Q_{10}$ is $0.87,0.9956$, 0.935 , and 0.92 , respectively, indicating good correlation between dependent and independent variables. The reduced models were developed for response variables by omitting the insignificant terms with $P>0.05$. The terms with $P<$ 0.05 were considered statistically significant and retained in the reduced model. The coefficients for full and reduced models for response variables are shown in Table 4 .

3.3. Full and Reduced Model for FLT. The significance levels of the coefficients $b_{1}, b_{12}, b_{11}$, and $b_{22}$ were found to be $P=$ $0.255,1,0.478$, and 0.603 , respectively, so they were omitted from the full model to generate a reduced model. The results of statistical analysis are shown in Table 4 . The coefficients $b_{0}$ and $b_{2}$ were found to be significant at $P<0.05$; hence, they were retained in the reduced model. The reduced model was tested in proportion to determine whether the coefficients $b_{1}, b_{12}, b_{11}$, and $b_{22}$ contribute significance information to the prediction of FLT [17]. The results of model testing are shown in Table 5 . The critical value of $F$ for $\alpha=0.05$ is equal to $9.12(\mathrm{df}=4,3)$. Since the calculated value $(F=0.73)$ is less than critical value $(F=9.12)$, it may be concluded that the interaction terms $b_{1}, b_{12}, b_{11}$, and $b_{22}$ do not contribute significantly to the prediction of FLT and can be omitted from the full model to generate the reduced model.

3.4. Full and Reduced Model for $Q_{6}$. The significance levels of the coefficients $b_{2}, b_{12}, b_{11}$, and $b_{22}$ were found to be $P=0.058,0.236,0.291$, and 0.443 , respectively, so they were omitted from the full model to generate a reduced model. The results of statistical analysis are shown in Table 4. The coefficients $b_{0}$ and $b_{1}$ were found to be significant at $P<0.05$; hence, they were retained in the reduced model. The reduced model was tested in proportion to determine whether the coefficients $b_{2}, b_{12}, b_{11}$, and $b_{22}$ contribute significance information to the prediction of $Q_{6}$. The results of model testing are shown in Table 5 . The critical value of $F$ 


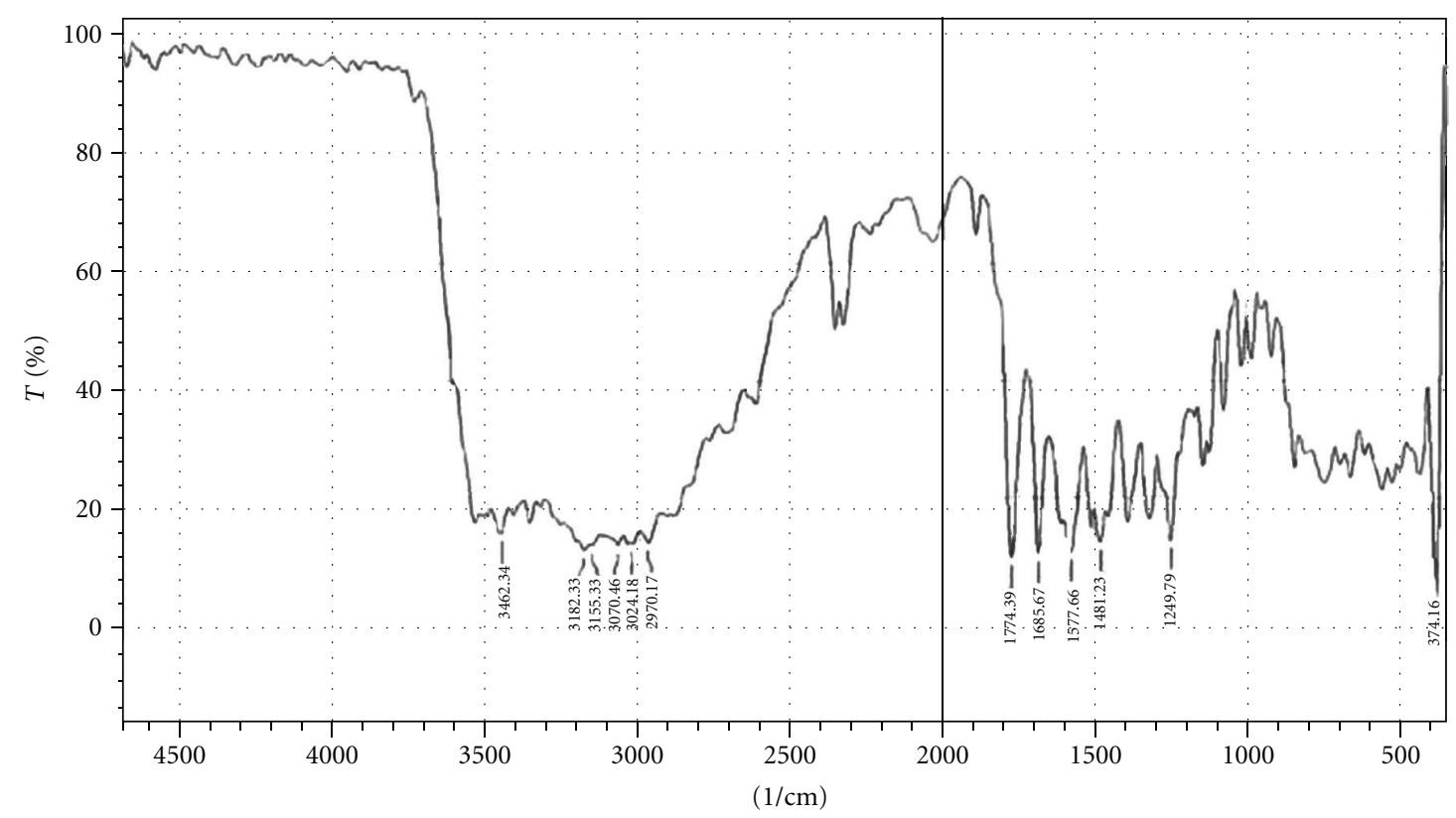

Figure 2: FTIR spectrum of amoxicillin.

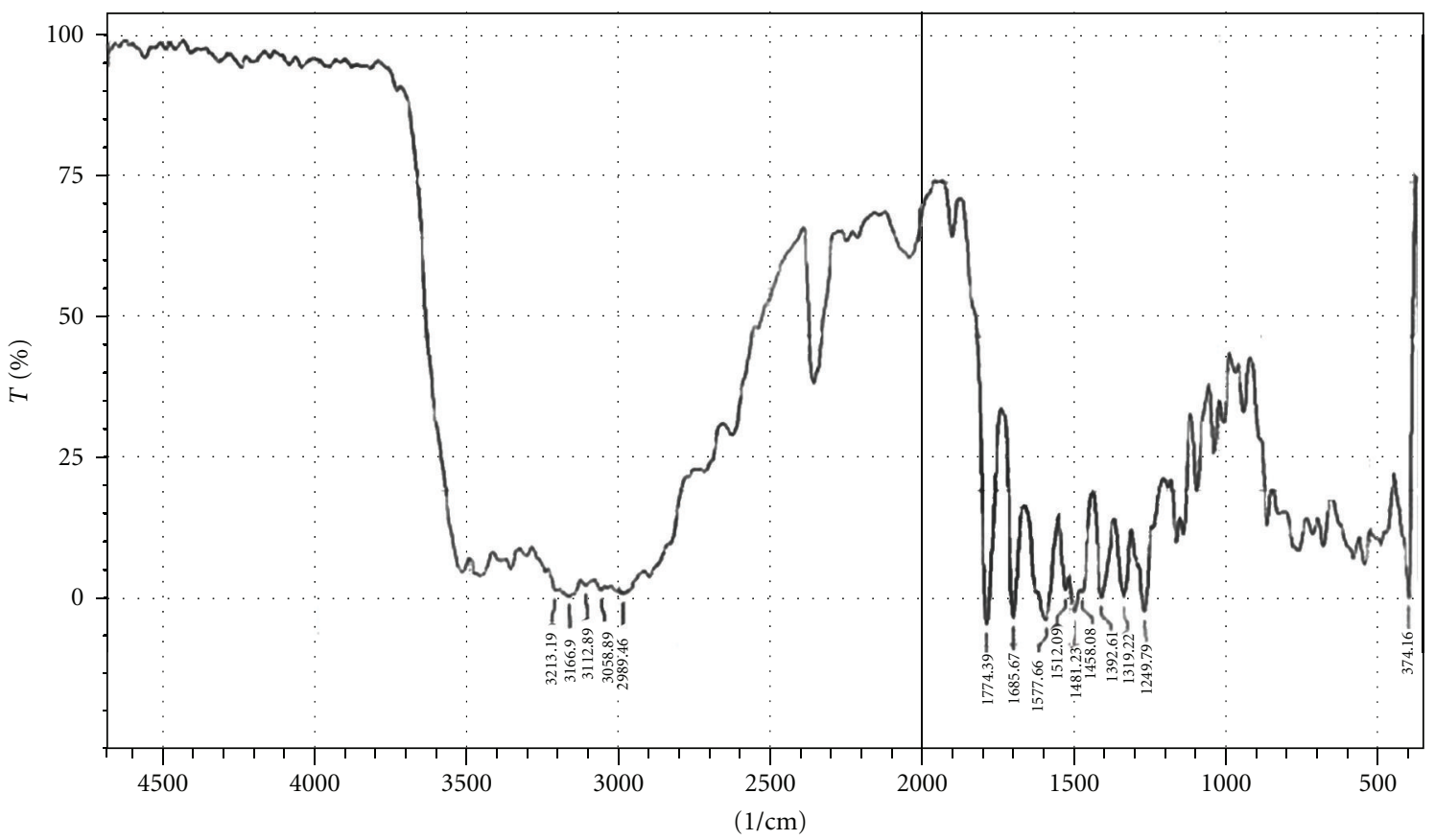

FIgURE 3: FTIR spectrum of amoxicillin and HPMC K100.

for $\alpha=0.05$ is equal to $9.12(\mathrm{df}=4,3)$. Since the calculated value $(F=3.36)$ is less than critical value $(F=9.12)$, it may be concluded that the interaction terms $b_{2}, b_{12}, b_{11}$, and $b_{22}$ do not contribute significantly to the prediction of $Q_{6}$ and can be omitted from the full model to generate the reduced model.

3.5. Full and Reduced Model for $Q_{10}$. The significance levels of the coefficients $b_{2}, b_{12}, b_{11}$, and $b_{22}$ were found to be
$P=0.120,0.104,0.109$, and 0.403 , respectively, so they were omitted from the full model to generate a reduced model. The results of statistical analysis are shown in Table 4. The coefficients $b_{0}$ and $b_{1}$ were found to be significant at $P<0.05$; hence, they were retained in the reduced model. The reduced model was tested in proportion to determine whether the coefficients $b_{2}, b_{12}, b_{11}$, and $b_{22}$ contribute significance information to the prediction of $Q_{10}$. The results of model testing are shown in Table 5 . The critical value of $F$ 


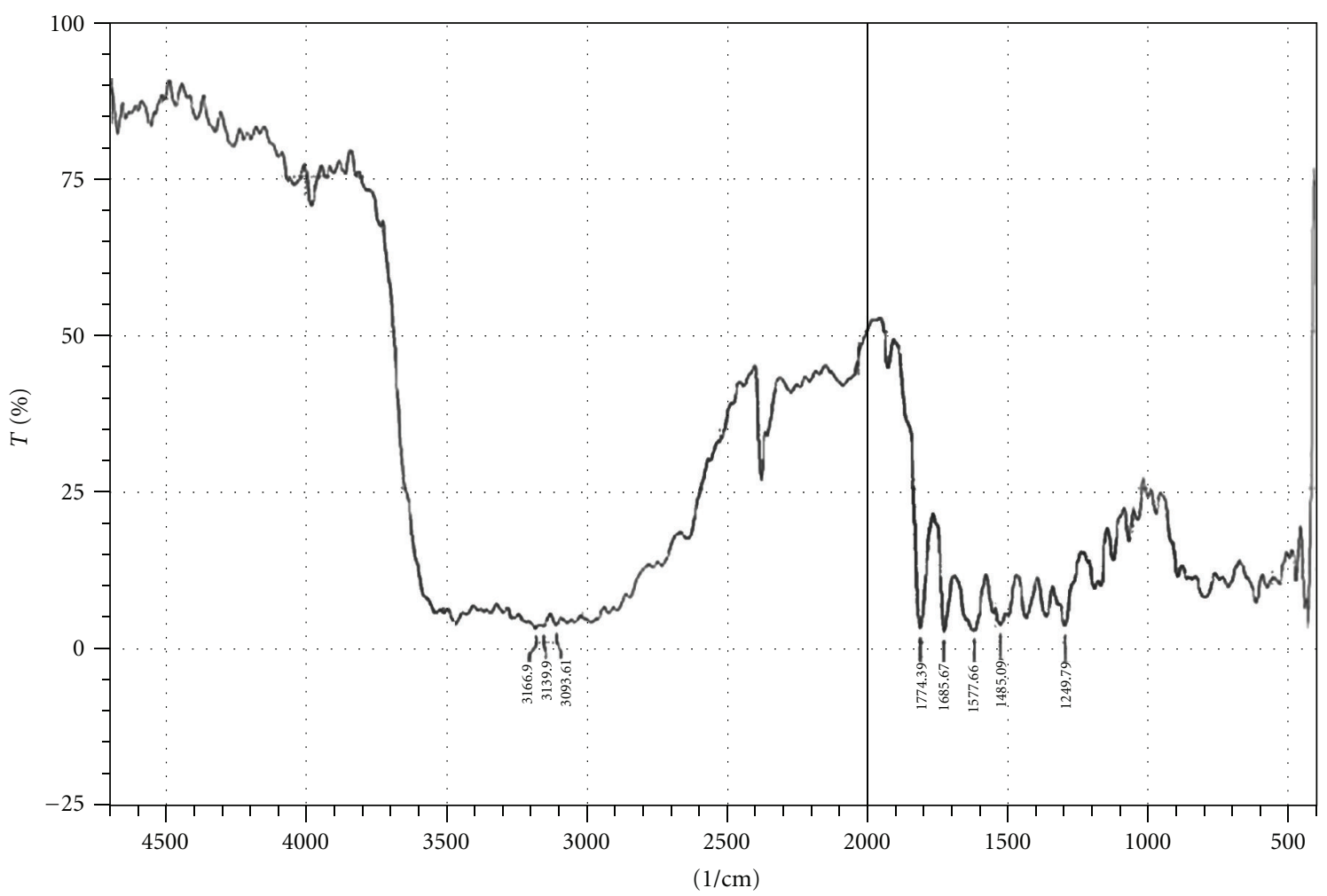

FIgURe 4: FTIR spectrum of amoxicillin and HPMC K100.

for $\alpha=0.05$ is equal to $9.12(\mathrm{df}=4,3)$. Since the calculated value $(F=3.99)$ is less than critical value $(F=9.12)$, it may be concluded that the interaction terms $b_{2}, b_{12}, b_{11}$, and $b_{22}$ do not contribute significantly to the prediction of $Q_{10}$ and can be omitted from the full model to generate the reduced model.

3.6. Kinetic Modeling of Dissolution Data. The kinetics of the dissolution data were well fitted to zero order, Higuchi model, and Korsemeyer-Peppas model as evident from regression coefficients (Table 6). In case of the controlled or sustained release formulations, diffusion, swelling, and erosion are the three most important rate controlling mechanisms. Formulations containing swelling polymers show swelling as well as diffusion mechanism because the kinetic of swelling includes relaxation of polymer chains and imbibitions of water, causing the polymer to swell and changing it from a glassy to rubbery state. The diffusion exponent $n$ is the indicative of the mechanism of drug release from the formulation. For a swellable cylindrical drug delivery system, the $n$ value of less than 0.45 is indicative of Fickian diffusionontrolled drug release, $n$ value between 0.45 and 0.89 signifies anomalous (non-Fickian) transport, $n$ value of 0.89 indicates case II transport, and $n$ value greater than 0.85 indicates super case II transport $[18,19]$. The value of diffusion exponent $n$ for all factorial formulations is less than 0.45 (Table 6) indicating Fickian drug release from the formulations.
3.7. Comparison of Release Profiles for Selection of Optimum Batch. The release profiles of the developed formulations are shown in Figure 1. The values of similarity factor $\left(f_{2}\right)$ for batches $F_{5}$ to $F_{9}$ were greater than 50 compared with theoretical release profile (Table 3 ) indicating good similarity in dissolution. The batch $F_{8}$ showed maximum value of $f_{2}$ (74.38) and hence was selected as optimum batch.

3.8. Fourier Transform Infrared Spectroscopy. Drug-excipients interactions play a vital role in the release of drug from formulation. Fourier transform infrared spectroscopy has been used to study the physical and chemical interactions between drug and the excipients used. The pure amoxicillin and its mixture with sodium alginate and HPMC K100 were mixed separately with IR grade $\mathrm{KBr}$ and were scanned over a range of $400-4500 \mathrm{~cm}^{-1}$ using FTIR instrument (FTIR1700, Shimadzu, Kyoto, Japan). The drug exhibits peak due to ketonic, primary amine, secondary amine, and hydroxyl (broad) group. It was observed that there were no changes in these main peaks in the IR spectra of a mixture of drug and polymers (Figures 2-4). The FTIR study revealed no physical or chemical interactions of amoxicillin with sodium alginate and HPMC K100 as evident from Figures 3 and 4.

\section{Conclusion}

Floating in situ gelling system of amoxicillin with increased gastric residence time can be formulated using sodium 
alginate as a gelling polymer and HPMC K100 as a thickening agent. The prepared formulation can provide a site-specific delivery of amoxicillin for 10 to $12 \mathrm{~h}$ with zero-order release kinetics.

\section{Acknowledgment}

The authors also thank Shri Sarvajanik Pharmacy College, Mehsana, for providing all other ingredients and required infrastructure for the conduct of this research work.

\section{References}

[1] B. S. Ramakrishna, "Helicobacter pylori infection in India: the case against eradication," Indian Journal of Gastroenterology, vol. 25, no. 1, pp. 25-28, 2006.

[2] G. H. Joel and E. L. Lee, "Agents for control of gastric acidity and treatment of peptic ulcers," in The Pharmacological Basis of Therapeutics, A. G. Gilman, J. G. Hardman, and L. E. Limbird, Eds., pp. 909-910, The MC Graw Hill, New York, NY, USA, 2001.

[3] T. A. Manuel and V. R. Leopoldo, "Assay of amoxicillin sustained release from matrix tablets containing different proportions of Carbopol 971P NF," International Journal of Pharmaceutics, vol. 273, no. 1-2, pp. 121-127, 2004.

[4] A. K. Hilton and P. B. Deasy, "In vitro and in vivo evaluation of an oral sustained-release floating dosage form of amoxycillin trihydrate," International Journal of Pharmaceutics, vol. 86, no. 1, pp. 79-88, 1992.

[5] N. G. Sonani, S. P. Hiremath, and S. A. Sreenivas, "Design and evaluation of gastroretentive mucoadhesive cephalexin tablets," Pharmaceutical Development and Technology, vol. 15, no. 2, pp. 178-183, 2010.

[6] N. H. Nagahara, A. M. Yohko, N. Masafumi, and T. Mayumi, "Mucoadhesive microspheres containing amoxicillin for clearance of H. pylori," American Society for Microbiology, vol. 42, no. 10, pp. 2492-2494, 1998.

[7] S. Miyazaki, N. Kawasaki, and M. Kubo, "Comparison of in situ gelling formulations for the oral delivery of cimetidine," International Journal of Pharmaceutics, vol. 220, no. 1-2, pp. 161-168, 2001.

[8] N. K. Ali and T. Anish, "In situ cross-linking of sodium alginate with calcium and aluminum ions to sustain the release of theophylline from polymeric matrices," Farmaco, vol. 59, no. 12, pp. 999-1004, 2004.

[9] N. M. Harish, P. Prabhu, and N. Charyulu, "Formulation and evaluation of in situ gels containing clotrimazole for oral candidiasis," Indian Journal of Pharmaceutical Sciences, vol. 71, no. 4, pp. 421-427, 2009.

[10] K. B. Wataru, M. Shozo, D. Masatake, and T. Mitsuo, "Oral sustained delivery of ambroxol from in situ-gelling pectin formulations," International Journal of Pharmaceutics, vol. 271, no. 1-2, pp. 233-240, 2004.

[11] USP 24 and NF 19. Rockville, MD: United State Pharmacopoeial Convention, Inc. 2000, 1941.

[12] G. A. Lewis, "Optimization methods," in Encyclopaedia of Pharmaceutical Technology, J. Swarbrick and J. C. Boylan, Eds., pp. 2458-2468, Marcel Dekker, New York, NY, USA, 1996.

[13] T. Higuchi, "Mechanism of sustained action mediation, theoretical analysis of rate of release of solid drugs dispersed in solid matrices," Journal of Pharmaceutical Sciences, vol. 52, pp. 1145-1149, 1963.
[14] A. W. Hixon and J. H. Crowell, "Dependence of reaction velocity upon surface and agitation," Industrial \& Engineering Chemistry Research, vol. 23, pp. 923-931, 1931.

[15] R. W. Korsmeyer, R. Gurny, E. Doelker, P. Buri, and N. A. Peppas, "Mechanisms of solute release from porous hydrophilic polymers," International Journal of Pharmaceutics, vol. 15, no. 1, pp. 25-35, 1983.

[16] P. Coasta, J. Manuel, and S. Labao, "Modelling and comparision of dissolution profiles," European Journal of Pharmaceutical Sciences, vol. 13, pp. 123-133, 2002.

[17] W. Mendenhall and T. Sincich, "Multiple regression," in $A$ second Course in Business Statistics, Regression Analysis, pp. 141-226, Dellen Publishing, San Francisco, Calif, USA, 1989.

[18] J. Siepmann and N. A. Peppas, "Modeling of drug release from delivery systems based on hydroxypropyl methylcellulose (HPMC)," Advanced Drug Delivery Reviews, vol. 48, no. 2-3, pp. 139-157, 2001.

[19] P. L. Ritger and N. A. Peppas, "A simple equation for description of solute release II. Fickian and anomalous release from swellable devices," Journal of Controlled Release, vol. 5, no. 1, pp. 37-42, 1987. 

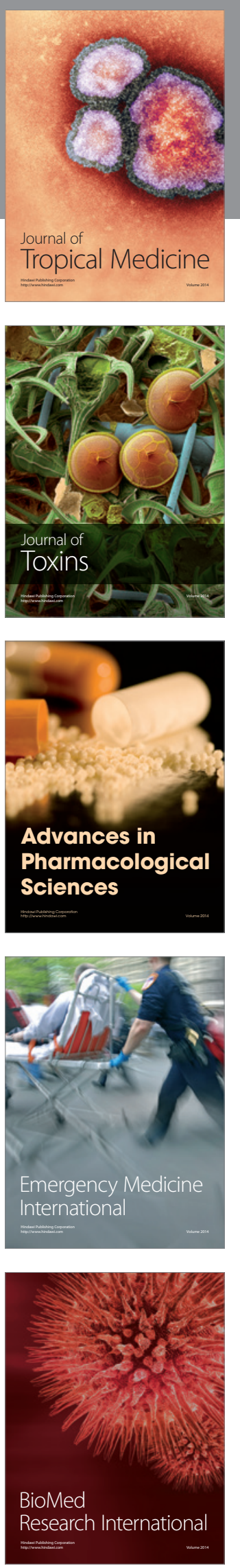
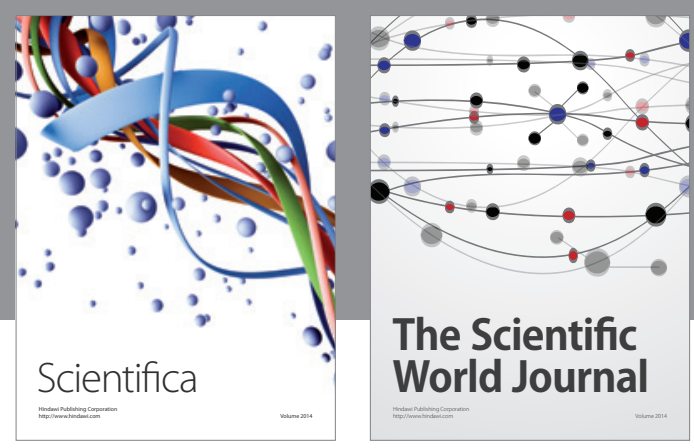

The Scientific World Journal
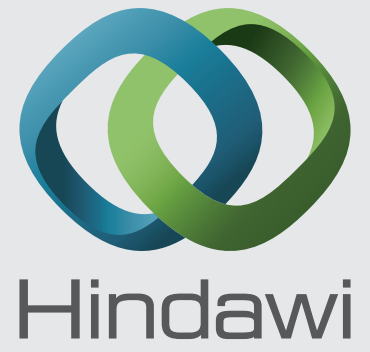

Submit your manuscripts at

http://www.hindawi.com
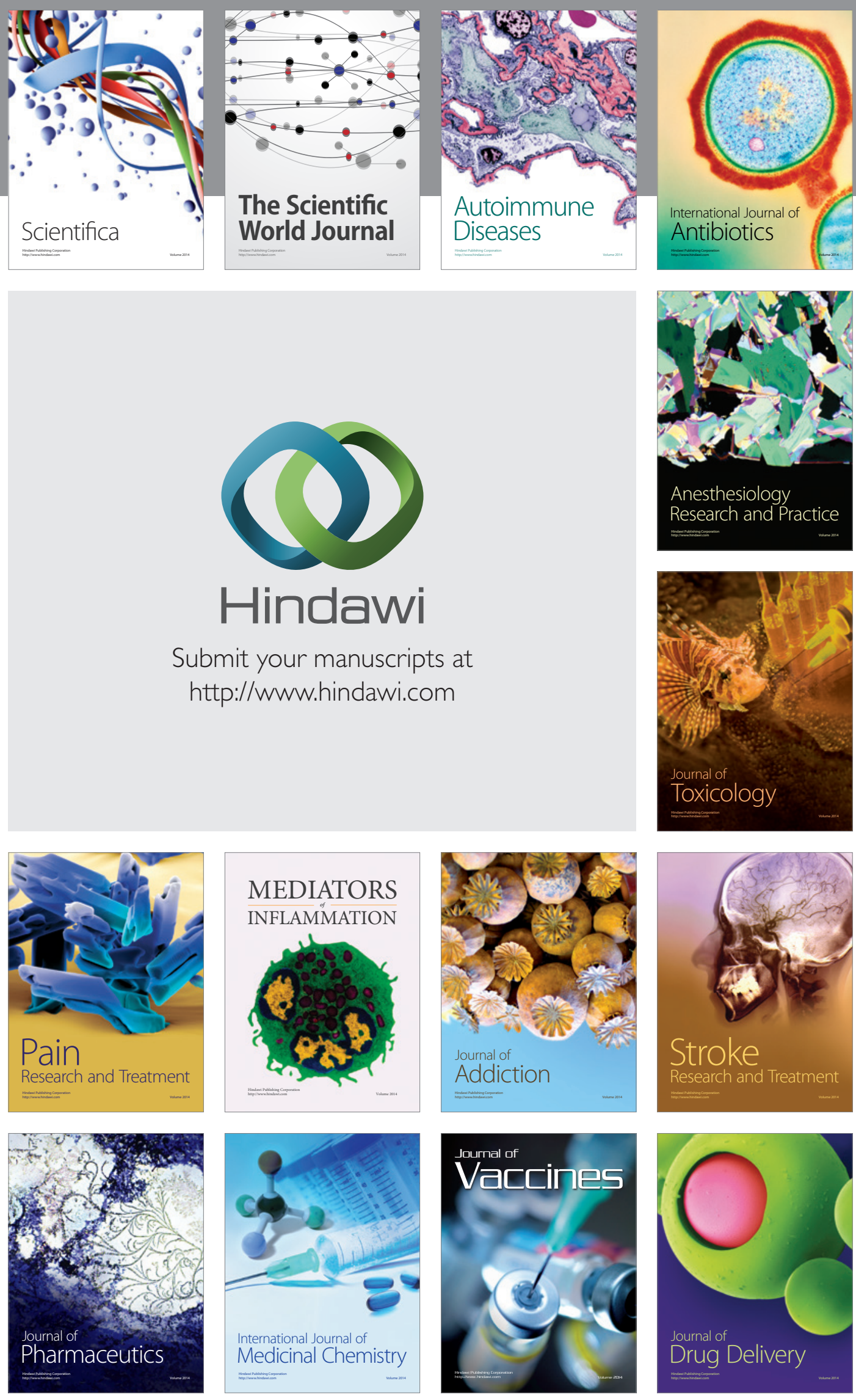